\title{
KADASTRO MAHKEMESİ KARARLARINA KARSI KARAR DÜZELTME YOLUNA BAŞVURULMASINDA MİKTAR VEYA DEĞER SINIRI ÜZERINNE BİR HGK KARARI
}

\author{
Ars. Gör. Sema Taspunar*
}

\section{OLAY}

Yargitay Hukuk Genel Kurulu (HGK), 1.11.1995 tarih ve E: 1995/16-576, K: 1995/899 sayılı kararı' ile Ceyhan İkinci Kadastro Mahkemesi'nce verilen 10/6/1993 gün ve 1990/88 E. 1993/19 say1lı kararın onanmasını kapsayan ve HGK' dan çıkan 15/2/1995 gün ve 1994/16-879 esas, 1995/78 karar sayılı ilâmın davacı vekili tarafindan karar düzeltilmesi yoluyla incelenmesi istemiyle ilgili olarak yaptığı usule ilişkin araştırma ile taşınmazın dava tarihindeki değerinin iki milyon liranın altında olması nedeniyle bu istemin reddine oy çokluğu ile karar vermiştir.

\section{HGK KARARI}

Ceyhan Kadastro Mahkemesi'nce verilen karar Yargitay ilgili dairesince bozulmuş, bozma üzerine mahkeme, kararında direnmiştir. Direnme kararının temyizi üzerine karar, HGK tarafından onanmıştır. Iş̧te bu onama kararına karşı davacı karar düzeltme isteminde bulunmuştur.

HGK, ikinci kez karar düzeltme istemiyle önüne gelen bu olayda öncelikle karar düzeltme yolunu tanımlayıp açıkladıktan sonra aşağıda ayrıntılı olarak belirteceğimiz gerekçelerle, somut olay bakımından taşınmazın dava tarihindeki değerinin bu yola başvurmaya olanak sağlamadığı sonucuna vararak, istemi oy çokluğu ile usulden (mesmu olmadığından dolayı) reddetmiştir.

* Medeni Usul tcra-Iflas Hukuku Anabilim Dalı Araştırma Görevlisi.

1. Karar için bkz. http: //yargitay.gov.tr/Mevzuat/emsal/9516-hgk.txt. 
Dava konusunun kadastro tesbitine itiraz olduğu olayda HGK, öncelikle karar düzeltme yoluna gidebilmek için belirli bir değer esası öngörülmüş olduğu için, bu değerin hangi tarih itibariyle dikkate alınacağı konusunu ön sorun olarak tartışmıştır. HGK, davada tek bir değer olacağı ve belirlenen bu değerin usule ilişkin tüm işlemlerde geçerli olacağı kuralını yineleyerek, karar ve inceleme tarihi değil, davanın açıldığı tarihte belirlenen değerin dikkate alınacağını açıklamıştır ${ }^{2}$. Somut olay bakımından da taşınmazın emlak vergisi değerinin değil ${ }^{3}$, davanın açıldığı tarihteki değerinin esas olduğu sonucuna varmıştır.

HGK kararda ayrica karar düzeltme kurumuna ilişkin genel bilgiler de vermiş, 1711 sayılı kanun ile yapılan değişiklikleri de kapsayan geniş açıklamalar yapmıştır.

HGK, belirlenen bu değerin ise taşınır-taşınmaz ayrımı yapılmaksızın karar düzeltmede ölçüt olacağını belirtmiştir:

"Ayrıca da, yasa koyucu temyiz yönünden kesinlik sinırın hükme bağlayan 427. maddede açıķa taşınır mal ve alacak davalarl demesine karsin, karar düzeltmeyi sintrlayan 440. maddesinin III. fikrasinda miktar veya degeri ............ liradan az olan davalara ait hilkümlerin onanmasi veya bozulmasına iliskin kararlardan söz etmis bulunmast, böylece taşıntr-taşınmaz mal davalan ayrımın öngörmemesi de bu görüşü doğrulamaktadır. Nitekim Hukuk Genel Kurulu, 15/2/1985 tarih ve 1984/8-32 Esas, 1985/94 sayll kararinda da "Karar düzeltmeye iliskin bu hïkmïn sadece para alacaklart için değil, taşınır ve taşınmaz mallara ait tüm davalar için de uygulanacă̆ını" açıkça benimsemistir."

\section{KARŞI OY YAZISI}

Üyelerden A. Özçelik ve 7. HD başkanı H. Örmeci karara katılmamış ve ikinci muhalif üye (7. HD başkanı) tarafından bir karşı oy yazısı kaleme alınmıştır. Örmeci, çoğunluk kararına özetle aşağıdaki gerekçelerle katılmamaktadır:

- Kadastro yapılmasının nedeni MK'na göre tapu sicilinin oluşturulmasıdır. Bu nedenle davacının gerçek değeri bildirme zorunluluğu yoktur. Her ne kadar taşınmazların değerinin belirlenmesinde emlak değerinin esas alınarak kadastro

2. "...karar dïzeltmenin yargılamanın bir aşaması olması ve her davada bir değer bulunması kuralı gözönuinde tutulduğunda, karar veya inceleme tarihindeki değerin belirlenmesi yolundaki göriłşlere de itibar edilemeyeceği kuşkusuzdur."

3. "Beyas edilmemesinin olanak diş1 olmaması itibarı ile emlak vergisi değerini esas

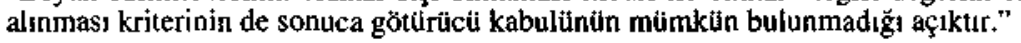


komisyonlarınca değerlerinin belirlenmesi hükme bağlanmış ise de ülkenin bulunduğu enflasyon ortamında bugün belirlenen gerçek değerin dahi yarın gerçeği yansıtmadığı açıktır.

- Davanın açıldığı tarihte kadastro davaları harca tabi olmadığından davanın taraflarının değer bildirme zorunluluğu yoktur. Mahkemenin belirlediği değer ise gerçek değeri göstermemektedir.

- Taşınmazların gerçek değerinin vergi, harç ve resim alım satımlardaki değerinin çok üstünde olduğu da bilinen bir gerçektir.

- HUMK m. 427 taşınmazlarla ilgili davalarda temyiz incelemesini değere bağlı tutmamıştır. Kanun koyucunun karar düzeltme yolunda da aynı yolu izlememesi ülke gerçeklerine uygun düşmez.

Bu nedenlerle karar düzeltme istemlerinin kadastro davaları ile ilgili ve sınırlı olmak koşulu ile değere bakılmaksızın kabul edilmesi gerekir.

\section{KARARIN İNCELENMESI}

\section{Giriş}

Herşeyden önce karar usul hukukunu ilgilendiren, maddi hukuka ilişkin bir tartışmanın yer almadığı bir karardır. Kararın veren ilk derece mahkemesi kadastro mahkemesi olduğundan öncelikle bu mahkeme hakkında kısaca bilgi vermek yararlı olacaktır.

\section{Kadastro Mahkemeleri}

Kadastro Mahkemeleri, Kadastro Kanunu'na göre kurulan, görevleri ve yargılama usulü bu kanunca belirlenen özel nitelikli ve geçici olarak etkinlik gösteren mahkemelerdir ${ }^{4}$ (3402 sayılı Kadastro $\mathrm{K} . \mathrm{m} .24 \mathrm{vd}$ ).

Kadastro mahkemeleri, bu kanunun uygulanmasını sağlamak üzere tek hakimden oluşan Asliye Hukuk Mahkemesi sıfatına sahip mahkemelerdir (3402 s. K. m. 24).

Kadastro Kanunu kadastronun amacını, "memleketin kadastral topografik haritasına dayalı olarak taşınmaz malların sınırlarının arazi ve harita üzerinde belirterek hukuki durumlarını tespit etmek ve bu suretle Türk Medeni Kanununun öngördüğü tapu sicilini kur-

4. Kadastro mahkemeleri hakkunda aynntılı bilgi için bkz. Baki Kuru, Hukuk Muhakemeleri Usulü El Kitabı, Istanbul 1995, s. 1027-1043; Lale Sirmen, Eşya Hukuku Dersleri, Ankara 1995, s. 165-166; Ramazan Arslan/SüLa Tanrıver, Yargı Örgütü Hukuku (Ders Kitabi), Ankara 1996, s. 29-30. 
mak" şeklinde açıklamaktadır ( 3402 s. K. m. 1). Bu amaçla bağlantılı olarak kadastro mahkemelerinin görevleri konu ve zaman bak1mından sınırlanmıştır. Zira bu mahkemeler, taşınmaz mal mülkiyetine ve sanırlı ayni haklara, tapuya tescil veya şerh edilecek veya beyanlar hanesinde gösterilecek sair haklara, sınır ve ölçü uyuşmazlıklarına, kadastroya ve tapu sicilini ilgilendiren benzeri davalara ve özel kanunlarca kendisine verilen işlere bakar (3402 s. K. m. 25/I). Kadastro mahkemelerinin bu konulara ilişkin görevi geçicidir. Nitekim, kadastro mahkemesinin görevi her taşnmaz mal hakkında kadastro tutanağının düzenlendiği günde başlar (3402 s. K. m. 26/I) ve bu bölgedeki kadastro işlemlerinin tamamlanmasına veya iş hacmi itibariyle kadastro mahkemesinin devamna gereksinim kalmadığının anlaşılması halinde Adalet Bakanlığı'nın dava dosyalarını taşınmaz malların bulunduğu yerin asliye hukuk mahkemelerine devretmesine kadar devam eder. Bu süre içerisinde tamamlanamayan davalara asliye hukuk mahkemesi Kadastro Kanunu'nun öngördư̆ğï usul ve esaslara göre devam edecektir (3402 s. K. m. 33/I).

Kadastro mahkemelerinde ayrıca açık hüküm bulunmadığı takdirde basit yargılama usulünün uygulanmasina (3402 s. K. 29/III) karşın, kadastro hakimi genel mahkeme hakimlerinden ayrı bir kısım yetkilere sahip olup hukuk davalarına egemen genel ilkelerden de bir kısım ayrılmalar gözlenmektedir'. Ancak bu mahkemelerde görülen davalar da harca tabidir. Buna göre, "Kadastro hakimi, dava harcl, yarglama giderlerinin tespit ve hesaplanmasinda ilgili taşınmaz mala ait son beyan dönemi emlak vergisi değerini esas alı" (3402 s. K. m. 36/II). "Kadastrosu yapilan yerlerde, emlak vergisi değeri belli olmayan taşınmaz mallara, kadastro ve dava harci ile yargilama giderlerine esas olmak üzere kadastro komisyonunca kıymet takdir edilir" (3402 s. K. m. 36/VI). Harca ilişkin bu genel hükümler dışında kanun yoluna ilişkin olarak da Kadastro Kanunu, kadastro mahkemelerinin kararlarına karşı asliye hukuk mahkemelerindeki usule göre bu yolların işletileceği hükmünï getirmiştir (m. 32/I).

\section{Kanun Yolları ve Özel Olarak Karar Düzeltme}

Kanun yolu, kararı veren ilk derece mahkemesi hakiminin yanılma olasılığına karşı bir üst mahkemeye başvurulması ve kararın

5. Kendiliğinden araşıtırma ilkesinin uygulanması ( $3402 \mathrm{s.}$ K. m. 30/I), kesin hükmïn üçüncủ kişileri etkilemesi ( $3402 \mathrm{~s}$. K. m. 34), HUMK m. 409'un uygulanmaması (3402 s. K. m. 29//), kadastro mahkemesi kararlarnn taraflara resen tebliz̧ edilmesi (3402 s. K. m. 32/) gibi. 
hukuki ve/veya maddi açılardan tekrar gözden geçirilmesini hedefleyen usuli bir araçtır ${ }^{6}$. Bu anlamda kanun yolunun bünyesinde iki özelliği barındırması gerektiği kabul edilmektedir: Bunlardan ilki, Suspensiv-(Hemmungs)wirkung adı verilen kanun yoluna başvurunun şekli anlamda hükmün kesinleşmesini engelleyici etkisidir. Kanun yolunun karakteristik ikinci özelliği ise, Devolutiv(Abwälzungs/Anfall)wirkung denilen uyuşmazlığı bir üst mercie aktarma etkisidir?

Doktrinde kanun yolları olağan ve olağan iistï olmak üzere ikiye ayrılmaktadır. Olağan kanun yoluna temyiz ve karar düzeltme yolları dahil edilirken, yargllamanın yenilenmesi olağanüstï kanun yolu kabul edilmektedir. Burada genel kabul gören ölçüt, kanun yoluna kesinleşmiş hükümlere mi, yoksa henüz kesinleşmemiş hükümlere karşı mı gidildiği hususudur. Yani karar düzeltme yolu icrayı durdurmamasına karşın hükmün şekli anlamda kesinleşmesini engellemektedir ${ }^{3}$. Ancak karar düzeltme yolunun kanun yolu olarak kabulüne de kararı veren merciin aynı kararı kendisinin gözden geçirmesi, yani kanun yollarında bulunması gereken hükmün bir üst merciiye aktarılması (devolutivwirkung) etkisinin eksik olmasi engel oluşturmaktadır. Bu nedenle de doktrinde bu yolun kendine özgü bir kanun yolu veya eksik kanun yolu olduğu belirtilmektedir".

6. Kun (El Kitabı), s. 761; Saim Üstündağ, Medeni Yargılama Hukuku, gözden geçirilmiş ve yenilenmiş 5. Bası, Istanbul 1992, s. 797; Sabri Şakir Ansay, Hukuk Yarglama Usulleri, yedinci baskı, Ankara 1960, s. 342; than E. Postacioglu, Medeni Usul Hukuku Dersleri, Istanbul 1959, s. 429; Doktrinde kanun yolu dar ve geniş anlamda olmak ïzere de tanımlanmıştır. buna göre geniş anlamda kanun yolu, "Aralanndaki uyuşmazlığı dava biçiminde yargı organı önüne getiren taraflara kanun tarafindan tanınan, bu dava ile ilgili olarak mahkemece verilen her tïrlï yargısal kararın tekrar gözden geçirilmesi, gerekli ise düzeltilmesini sağlayan bir olanak" olarak tanımlanmıştır. Ramazan Arslan, Medeni Usul Hukukunda Yargılamanın Yenilenmesi, Ankara 1977, s. 8. Konunun inceleme sınırlanı aştığından dar ve teknik anlamda kanun yolu kavramı hakkında aynntılı bilgi için bkz. Necip Bilge, Medeni Yargslama Hukukunda Karar Dizeltme, Ankara 1973, s. 3-11; Meral Sungurtekin, Karar Düzeltmenin Kanun Yolu Niteliğgi ve Karar Düzeitme Dilekçesinde Sebep Gösterme Zorunluluğu Bulunup Bulunmadığı Meselesi, YD, c. 16, sa. 4, s. 471 487.

7. Thomas/Putzo, ZPO mit GVG, den Einführungsgesetzen, EuGVỦ und AVAG, 21. neubearbeitete Auflage, Mitnchen 1998, s. 791; Baumbach/Lauterbach/Albers/ Hartmann, Zivilprozessordnung, 57. neubearbeitete Auflage, München 1999, s. 1381; Üstündă, s. 797; Sungurtekin, s. 474-476.

8. Kuru (El Kitabi), s. 761-762. Ancak doktrinde bu ayrımın ölçútleri üzerinde bir anlaşma olmadiğı da gözlenmektedir. Bu ölçütler ve eleştirisi için bkz. Necip Bilge, Medeni Yargilama Hukukunda Karar Düzeltme, Ankara 1973, s. 104-111; Sungurtekin, s. 477.

9. Kuru (El Kitabı), s. 844; Selçık Öztek, HUMK m. 427'deki Kesinlik Sınırının Temyiz Kanun Yolunun Amacı Bakımından Değerlendirilmesi ve Anayasa Mahkemesi- 
Bütün bu genel açıklamalardan sonra karar düzeltme kurumunu, "hüküm mahkemelerinin nihai kararları üzerine, temyiz incelemesi sonucunda verilen yargıtay kararlarının aynı kurulda tekrar incelenmesini sağlamaya yarayan bir kanun yolu" olarak tanımlamak mümkündür' ${ }^{10}$. Türk Hukuku'na özgü bir yol olan ve ülkemizdeki istinaf mahkemelerinin boşluğunu doldurmak anlamında bir işlev üstlenen bu kurumun davalann uzamasına neden olduğu gerekçesiyle kaldıılması gerektiği de doktrinde savunulmaktadır".

Yargitay dairelerinin veya Hukuk Genel Kurulu'nun vermiş olduğu kararları tekrar kendisinin incelemesini ifade eden karar düzeltme, temyiz kanun yolunun bir devamı olmakla birlikle birtakım sınırlamalara bağlı tutulmuştur. Herşeyden önce karar düzeltme nedenleri sayılmış (HUMK m. 440/I, 1-4) ve taraf iradesi ile bağlılık

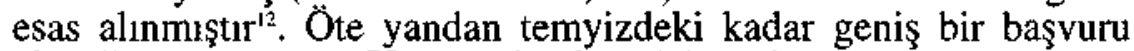
olanağı tanınmamış, Yargıtay'ın hangi kararlarına karşı karar düzeltme isteminde bulunulamayacağı hükme bağlanmıştır (HUMK m. 440/III, 1-4). Buna göre parasal olarak belli bir miktarın altunda kalan davalara iliş̧kin (1.1.1998 tarihinden sonra açılan davalarda 300 milyon lira) Yargıtay'ın onama veya bozma kararlarına karşı karar düzeltme isteminde bulunulamaz (HUMK m. 440/III, 1). Ayrica karar düzeltme yolu kural olarak asliye hukuk mahkemesince verilen kararlara karşı Yargıtay'ın vermiş olduğu kararlara karşı gidilebilen bir yoldur ${ }^{13}$.

nin 20.1.1986 tarihli Kararı, Hukuk Araştırmalanı Dergisi, c. 2, sa. 2, s. $62-74$ (62); Saim Ustündaš, 1711 Sayılı Kanunun Kanun Yolları Bakımından Getirdiği Değişiklikler ve Bunların Değerlendirilmesi, HUMK'nu değiştiren 1711 Sayılt Kanun ve Noterlik Kanunu hakkinda Sempozyum, tstanbul 1976, s. 129-160 (130). Doktrinde ist bir mahkemeye aktarma etkisinin eksikliğinin onun kanun yolu olma özelliğini ortadan kaldırmadığı, bunun sadece bir ülkenin yargı örgütü ile ilgili oldugu belirtilmektedir. Bu konuda bkz. Bilge, s. 107; Sungurtekin, s. 480; Karar düzeltmenin kararı veren merciden istenmesinin onun bir zaafı değil, özelliği olduğu, karan vermis hakimlerin kendi yanlışlarından dönmelerinin adaletin sağlanmasına hizmet ettiği görüşü için bkz. Burhan Gürdoğan, Tashihi Karar Müiessesesi, Prof. Dr. Ahmet Esat Arsebilk Armağanı, Ankara 1958, s. 285-306 (286-287).

10. Bilge, s. 102.

11. Kuru (El Kitabs), s. 844; Baki Kuru, "Bugünkü Yapısı tçinde Yargıtay'ın İş Yüküunü Azaltma Careleri", Yargitay in Kuruluşunun 120. Yılı Sempozyumunda Sunulas Bildiri, YD, c. XV, sa. 1-4, s. 37 vd.; Ústündağ, s. 878. Bu kurumun lehinde ve aleyhinde göruşler jçin bkz. Ömer Berki, A. Recai Seçkin'e Armağan, Ankara 1974, s. 143-190 (148-149); Bilge, s. 90-97; Kemal Demiroğlu, Hukukta Tashíhi Karar, Ankara 1945, s. 37-38.

12. Temyizde ise Yargitay, tarafların belirtmediği ancak kanuna aykın bir nedenden dolayı da kararı bozabilir (HUMK m. 439/II).

13. Karar düzeltme isteminde bulunulabilecek sulh hukuk mahkemesi kararłan mirasçlık bejgesi verilmesine iljşkin kararlar ve kira sözleşmesine dayanan tahliye, akđin feshi davaları ve bu davalarla açıımıs kira alacağı ve tazminat davaları ve bunlara 


\section{Esası \\ 4. Kanun Yollarına Başvurmada Değer veya Miktar}

Yukarıda karar düzeltme yoluna başvuruda bir parasal sinırın varlığına dikkat çekilmişti. Bundan önce, esas olarak alacak veya taşınırlara ilişkin bir mahkeme kararını temyiz edebilmek için de bu davaların (veya istemin kabul edilmeyen kesiminin) değerinin 20 milyon lirayı geçmesi gerekir (HUMK m. 427/II, IV). Uyuşmazlığın değerine göre kanun yolunu açan veya kapayan bu sisteme "değere dayalı temyiz sistemi" adı verilmektedir ${ }^{14}$. Buna göre de taşınmazlara ilişkin davalar, taşınmazın değerine bakılmaksızın, temyiz yoluna gidilebilecek davalardır.

Pozitif hukuk bakımından kanun yoluna başvuru hakkının s1nırlanıp, verildiği anda kesin olan kararlar kategorisi yaratmanın anayasaya aykırı olduğu ileri sürülmüs, ancak Anayasa Mahkemesi, sözkonusu sınırın Yargıtay'ın iş yükünü azalttığı, bu nedenle de kamu yararına hizmet ettiği gerekçesiyle başvuruyu reddetmiştiris ${ }^{i}$. Doktrinde bu karar, hak arama özgürlïğünü kısıtladığı, yargılamanın amacına aykırı olduğg ${ }^{16}$; Anayasa Mahkemesi'nin Yargitay'in gerçek işlevini belirlemeden olan ve olması gereken hukuk çözümlerini birbirine karıştırdığı ${ }^{17}$; temel hakların sınırlanmasında yol

karșı açılmış karşı davalar ve Kat Mülkiyeti Kanunu'ndan doğan davalarla sınırlanmiştır (HUMK m. 440/II, 2).

14. Öztek, s. 63; Ustündă (Sempozyum), s. 135.

15. "...ttiraz konusu kuralla, davların süratlendirilmesi ve Yargıtayın yükünün bir ölçı̇de azaltılması amaçlanmıştr. Getirilen sınırlama kamu yararına yönelik bulunmaktadır. Türk parasının bugülnkü satın alma gücü karşısında yüzbin liralık kesinilik sınırının adalet duygusunu rencide edecek, dolayısıyla hukuk devleti ilkesini zedeleyecek ölçüye ulaştığını söylemek mümkün değildir". "... Anayasanın 2. Maddesinde öngörülen hukuk devleti ilkesi, konulacak kurałlarda adalet ve hakkaniyet ölçülerinin gözönünde tutulmasını gerektirir. Ancak, kamu yaran gerektírdiğinde bazı hükümler iç̧ı kanun yollarına başvurmanın önlenmesi mümkiùndür. ... Yargı yerlerince yapilacak incelemeler sonunda verilecek kararlardan hangisinin kesin olduğunun belli edilmesi dahi anilan madde hulkmü ile Anayasadaki temel ilkelere ve güvence kurallanna aykırı olmanak üzere yasakoyucunun takdirine bırakılmuşıtır. Adliye mahkemelerinin kimi karar ve hïkümleri için Yargıtay yolunun kapatılmasınu öngören bir yasa kuralının hukuk devleti kavramıyla bağdaşmayacak sonuçlara yol açma olanak ve olasılığını doğuran bir nitelik arzetmedikçe bu kavramla çelişkiye dủstüğlunden sőz edilemez." 20.1.1986 tarih ve 23/2 sayıli, HUMK m. 427/Ir, III ve IV'un anayasaya aykırı olmadığ şeklindeki Anayasa Mahkemesi kararı için bkz. RG 16.4.1986, sa. 19080.

16. Ejder Ylmaz, Hukuk Davalarında Yasayollarına Başvuru Hakkı ve Bu Hakkın $S_{1}-$ nırlandınlmasının Yerindeliğ̣ Sorunu, Tutrkiye Barolar Birliği Dergisi, 1988, sa. 1, s. 131-155.

17. Ötek, s. 63, 65-67. 
gösterici olan ölçuilülük ilkesini irdelemeden sonuca ulaştığ1 ${ }^{18}$ şeklindeki gerekçelerle eleştirilmiştir.

\section{Taşınmażiara İlişkin Davalarda Karar Düzeltme Yoluna Başvurmada Değer Esası ve Bunun Belirlenmesi}

Karar düzeltme bakımından da kanun koyucunun ilk defa 1711 sayll kanunla parasal bir sınır getirdiğini ve bunun da Yargıtay'ın iş yükünün azaltılması amacıyla yapıldığını görmekteyiz ${ }^{19}$. Burada kanun koyucu değeri belli bir miktarın altında kalan her türlü (alacak, taşınır ve taşınmaz) davayı karar düzeltme yolundan hariç tutmuştur. Hatta doktrinde temyiz yolundaki kesinlik sınırına taşınmazların da dahil edilmesi gerektiği savunulmuştur ${ }^{20}$.

Kanaatimizce pozitif hukukun bu düzenlemesi şu bakımlardan eleştiriye açıktır: Öncelikle karar düzeltme yolu, tam anlamıyla olağan kanun yolu ölçutlerine uygun olmamakla birlikte temyizden sonra başvurulabilen, bir anlamda onun devamı sayılabilecek olan bir kanun yoludur. Temyizde veya genel olarak bir kanun yolunda değere dayalı sınır yaratmanın mantığı, kendisinden kolaylıkla vazgeçilebilmesinde yatar. Yani kişi, kesin hüküm sonucu kaybettiğine inandığı ekonomik değerden kolaylıkla vazgeçebilir olmahıdır" Kanun koyucu taşınır veya alacak davalarında böyle bir varsayımdan hareket etmekte haklı sayılabilir. Oysa taşınmazlara iliş̧in davalarda bu sonuca varmak güçtür. Kaldı ki, kadastroya ilişkin davalar ülkenin kadastral haritasının yapılması, tapu sicilinin oluşturulmasına hizmet eder. Öte yandan Türk Hukuku'nda istinaf yolunun bulunmaması nedeniyle, gerek temyiz gerekse karar diizeltme yolları adeta bu boşluğu dolduracak şekilde amacı aşacak ölçüde geniş bir uygulama alan bulmaktadır. Nitekim, "Yargıtay kararının usul ve kanuna aykırı bulunması"nın bir karar düzeltme nedeni sayılması bunun açık örneğini oluşturur. Bu nedenle Türk Hukuku'nda "somut olay adaletinin gerçekleştirilmesi" veya "ülkede hukuk birliğinin sağlanması (yeknesaklaştırılması)" amaçları birarada uygulanmaya çalışılmaktadı ${ }^{22}$. O nedenledir $\mathrm{ki}$, aslında istinaf mahkemeleri sisteminde haklılık kazanan değere dayalı temyiz

18. Hayrettin Ökçesiz, Yargıtay'ın İsyükï̀ün Hafjfletilmesinin Bir Aracı Olarak HUMK'nun 427. Maddesi Üzerine, Hukuk Araştırmalan Dergisi, c. 2, sa. 2, s. 75-79.

19. Baki Kuru/Ramazan Arslan, 1711 sayılı Kanunun Kanun Yolları Bakumından Getirdiği Değişiklikłer ve Bunların Değerlendirilmesi, HUMK'nu değiştiren 1711 Sayılı Kanun ve Noterlik Kanunu hakkunda Sempozyum, Istanbul 1976, 161-183 (180).

20. Kuru/Arslan (Sempozyum), s. 167.

21. Ökçesiz, s. 78 .

22. Ötek, s. 67. 
veya kanun yolu sistemi, ülkede içtihat birliği sağlama işlevini üstlenen ve belli bir değerin ỉstündeki uyuşmazlıklar için bunu gerçekleştiren, ancak bu değerin altındaki davalarda yeknesak hukuk amacından vazgeçen bir anlayışla bağdaştırılamaz. Bir yargı örgütü sorunu olan bu tercih, görüldügüu gibi önemli yorum farklılıklarına yol açabilmektedir.

Karar düzeltme istemlerinin sınırlanmasının Yargıtay'ın işyükünïn azaltılmasına ve bunun da kamu yararına uygun olduğu tezi de, en azından taşınmaz davaları için eleştiriye açıktır. Bir kere öncelikle tapu sicilinin tutulmasındaki kamu yararı ve Yargıtay'ın yoğunluğunun giderilmesi konuları karşılaştırıldığında herhalde ilkinin önemi yadsınamaz. Kaldı ki, bu sınırların varlığına karşın Yargıtay sürekli olarak bir iş yoğunluğu içinde bulunmaktadır. Dolaytsıla bu tür düzenlemeler "hissedilir" bir rahatlama da getirmemektedir ${ }^{23}$.

Kanun koyucunun temyizde olduğu gibi karar düzeltmede de taşınmaza ilişkin davaları ayrık tutmamasının, bu sınırların çok yükssek olarak belirlenmemesi, dolayısıyla da belki de uygulamada gündeme gelmeyeceği düşünülmüş olabilirse de, daha az olan temyiz sınırında taşınmazın açıkça belirtilmesi bu görüşüi kabule engeldir. Bu düzenleme kanaatimizce kamu yararına uygun düşmemektedir. Kanun koyucunun bu sınırı enflasyona bağlı olarak düzenli olarak yükselttiği (HUMK'a 4146 s. K. ile eklenen Ek m. 3) dikkate alınırsa, alacak veya taşınır davalarında olduğu gibi bir kısım davaların önemli bir bölümünün ise yoksun kalınabilecek düzeyde olduğu iddia edilemez. Zira burada taşınmazlar söz konusudur.

Öte yandan kararda belirtilen taşınmazın değerinin belirlenmesine ilişkin konuya da, karar düzeltme istemininin kabulüne engel olması nedeniyle değinmek gerekir. Bilindiği gibi malvarlığına ilişkin davalarda bir değer belirlenir ve bu başta mahkemenin görevinin belirlenmesi (HUMK m. 2/I ${ }^{24}$ ) olmak üzere davanın bundan sonraki aşamalarında dikkate alınır. Burada taşınmazın değerinin belirlenmesi görev açısından önem ve özellik göstermez. Zira kadastro mahkemesinin görevi, taşınmazın değerinden bağımsız olarak belirlenmiştir. (3402 s. K. m. 25, 26). Ancak bu davalar da harca tabidir ve kanun gerek harç, gerekse yargılama giderleri açısından özel bir düzenleme getirmiştir. Buna göre, kadastro hakimi

23. Ökçesiz, s. 78.

24. Konusu paradan başka birşey olan davalarda tarafların anlaşması ile hakimin bağlı olamayacağı hakkında bkz. Kuru (El Kitabı), s. 92. 
dava harcı, yargılama giderlerinin tespit ve hesaplanmasinda ilgili taşınmaz mala ait son beyan dönemi emlak vergisi değerini esas alır. Kadastrosu yapılan yerlerde, emlak vergisi değeri belli olmayan taşınmaz mallara, kadastro ve dava harcı ile yarglama giderlerine esas olmak üzere kadastro komisyonunca klymet takdir edilir (3402 s. K. m. 36/I, II ve VI). Yargllamada belirlenecek değer birden fazla olamayacağı ve bu da görev, yargılama gideri, harç, vekâlet ücreti ve kanun yollarına başvurmada esas alınacağı için bu değerin belirlenmesinde hakim söz sahibi olup, tarafların iradesi onu bağlamayacaktır. Ancak 3402 sayılı kanunun belirtilen hükmü emredici bir düzenlemeyi mi getirmektedir? Yani hakim taşınmaza ilişkin son emlak vergisi değerini esas almak zorunda mıdır? Kanaatimizce 3402 sayılı kanunun mali hükümler başlığı altındaki bu hükmünü, hakimin paradan başka bir malvarlığg değerine ait davalarda dava konusunun değerini serbestçe takdir etmesi kuralı karşısında sadece ona yol gösterici bir ölçüt değeri izafe etmek doğru olur. Zira ülkemizde emlak vergisine esas alınan değerin çok defa gerçeği yansıtmadığı bir gerçektir. Böyle bir değeri yargılamaya temel almak ve buna bağlı olarak da o davada karar düzeltme yoluna gidilip gidilmeyeceğini belirlemek adil olmayan sonuçlara yol açar. Bu nedenle hakimin taşınmazın davanın açıldığı tarihteki gerçek değerini belirlemesi gerekir. Incelediğimiz karar da göstermektedir ki, taşınmazın kabul edilen değerine göre, taşınmazlar için göreli olarak çok düşük rakamlan ifade etmesine karşın, yasal karar düzeltme sınırı altında kalabilen taşınmazlar bulunabilmektedir. Bu nedenle de olması gereken hukuk bakımından taşınmaz davalarında en azından kadastro mahkemeleri örneğinde olduğu gibi ayni haklara ilişkin bu tür davalarda değer esasından vazgeçilmelidir. Bu anlamda karşı oy görüşüne hak vermemek mümkün değildir.

\section{SONUÇ}

Karar düzeltme kurumunun yarar veya sakıncaları, kaldırılması veya korunması konusunda fikir beyan etmekten çok bu çalışmada amacımız, bu sistemin kendi mantığı içinde taşınmaz davalarının özellikle aynî hakka ilişkin olmak üzere, değerine bakılmaksızın karar düzeltme istemlerine konu olabilmesi gerekliliği üzerinde durmaktır. Yoksa sisteme ilişkin eleştiri ve değişiklik önerilerinin dikkate alınması halinde çok farklı sonuçlara varmak mümkün olacaktır. 